\title{
Role of Mammalian Chitinases in Asthma
}

\author{
Lim Shuhui ${ }^{a}$ Yu-Keung Mok ${ }^{b}$ W.S. Fred Wong ${ }^{c, d}$ \\ ${ }^{a}$ Cell Division and Cancer Laboratory, Institute of Molecular and Cell Biology, Agency for Science, Technology \\ and Research, ${ }^{b}$ Department of Biological Sciences, Faculty of Science, ' Department of Pharmacology, \\ Yong Loo Lin School of Medicine, and ${ }^{\mathrm{d}}$ Immunology Program, Life Sciences Institute, National University \\ of Singapore, Singapore, Singapore
}

\section{Key Words}

Chitin - Acidic mammalian chitinase $\cdot$ YKL-40 .

Corticosteroid $\cdot$ Cysteinyl leukotriene receptor antagonist

\begin{abstract}
Asthma is a chronic inflammatory disease characterized by airway inflammation, mucus hypersecretion and airway hyperresponsiveness. Mechanisms underlying the pathogenesis of asthma are not fully understood. In recent years, there are mounting evidences demonstrating that mammalian chitinases may play a key role in mediating the T-helper 2 cell-driven inflammatory response that is commonly associated with asthma. Chitinases (e.g., chitotriosidase and acidic mammalian chitinase) are enzymes that degrade chitin, the second most abundant biopolymer that can be found in the cell walls of fungi, microfilarial sheaths of helminths, and exoskeletons of insects and crustaceans. There are also chitinase-like proteins (e.g., YKL-40, Ym1 and Ym2) that lack chitinolytic activity but retain chitin-binding ability. Therefore, chitinases were originally believed to function in host defense against parasitic infections, but the first discovery of their role in inflammatory airway diseases came as a surprise. There is ample evidence to support an association of acidic mammalian chitinase and YKL-40 with allergic bronchial asthma in patients. Our recent studies in a mouse asthma model revealed that anti-inflammatory drugs like corticosteroid and cysteinyl leukotriene receptor antagonist were able
\end{abstract}

to suppress elevated pulmonary levels of mammalian chitinases. Taken together, mammalian chitinases may be useful as biomarkers for asthma. Notwithstanding, large-scale multi-center association studies are required to confirm this hypothesis. Besides, substantially more works using knockout mice, recombinant chitinases and siRNA technology are required to investigate a potential role of chitinases in the pathogenesis of asthma.

Copyright $\odot 2009$ S. Karger AG, Basel

\section{Introduction}

Asthma is one of the most common chronic diseases in the world, affecting people of all ages and ethnic backgrounds. As many as 300 million people around the world suffer from asthma, and it is projected that this number will increase to 400 million by year 2025 as more countries become urbanized $[1,2]$. Although asthma is generally not a life-threatening disease, mortality rates associated with it are still considerable, accounting for about 1 in every 250 deaths worldwide [3]. Asthmatics require continuous medical care, and hence, the world is further laden with an enormous economic burden, both in terms of direct medical expenses and indirect costs such as work days lost and mortality. For an idea of the magnitude of the problem, a recent report [4] revealed that the total cost of asthma in the United States was approxi-

\section{KARGER}

Fax +4161306 1234

E-Mail karger@karger.ch

www.karger.com (c) 2009 S. Karger AG, Basel

$1018-2438 / 09 / 1494-0369 \$ 26.00 / 0$

Accessible online at:

www.karger.com/iaa
Correspondence to: Prof. Dr. W.S. Fred Wong

Immunology Program, Center for Life Sciences

National University of Singapore

28 Medical Drive, No. 03-05, Singapore 117456 (Singapore)

Tel. +65 6516 3263, Fax +65 6873 7690, E-Mail phcwongf@nus.edu.sg 
mately USD 12 billion and that in Europe, it was about USD 21.6 billion per year. Taken together, this fuelled intensive research in an attempt to better understand the pathogenesis of asthma and to formulate more effective diagnostic and therapeutic strategies that can hopefully aid in relieving the global burden of asthma. Chitinases are among one of the recently described proteins suggested to play a pivotal role in T-helper 2 (Th2)-mediated inflammation and allergic diseases such as asthma [5].

\section{Chitin}

Chitin, similar to cellulose, is a polysaccharide comprising of repeating monomeric units linked together by $\beta(1 \rightarrow 4)$ glycosidic bonds. The hydroxyl group of each Dglucose residue is replaced by an acetylamine group in chitin to form $\mathrm{N}$-acetyl-D-glucosamine. This substitution allows for increased hydrogen bonding between adjacent polymers, giving the chitin-polymer matrix increased strength [6]. While cellulose lends structural support to plant cell walls, chitin provides architectural reinforcement to the cell walls of fungi, microfilarial sheaths of helminths and exoskeletons of insects and crustaceans (fig. 1). Collectively, it has been estimated that these organisms produce more than 1 billion tons of chitins per annum, making it the second most abundant biological polymer after cellulose [7].

\section{Mammalian Chitinases}

Chitinases are enzymes that catalyze the hydrolysis of the $\beta(1 \rightarrow 4)$ glycosidic bonds in chitin, thereby dismantling its polymeric structure. Accordingly, organisms will require chitinolytic activity in 3 different scenarios. First, organisms that are encrusted by a tough layer of chitin express chitinases during specific developmental phases to aid in the remodeling of their biological matrices so as to accommodate changes in body size and shape. Second, organisms that consume other chitin-containing organisms as a source of food express chitinases to digest the insoluble chitin polysaccharide into absorbable metabolites from which energy is derived. Third, organisms that are prone to infection by chitin-coated microorganisms express chitinases to degrade the protective shield of the invading pathogens, thereby uncovering the susceptible inner core to attacks that ultimately lead to death and expulsion from the host body. Since mammals do not produce a chitinous structure nor have been shown to depend on chitin as an energy source, the first discovery of the involvement of acidic mammalian chitinase (AMCase) in the pathogenesis of asthma was novel and unexpected [8].

Mammalian chitinases belong to the evolutionary conserved family 18 of glycosyl hydrolases (GH18), which can be further subdivided into enzymatically active true chitinases and chitinase-like proteins that have no enzymatic activity but retain chitin-binding activity $[9,10]$. The N-terminal catalytic domain of GH18 family members adopts the triose-phosphate isomerase fold which is characterized by the $(\beta / \alpha)_{8}$-barrel structure (fig. 2). Within this barrel, the $\beta_{4}$ strand contains a conserved sequence motif (DXXDXDXE, where D = aspartic acid, $\mathrm{E}=$ glutamic acid, and $\mathrm{X}=$ any amino acid) that forms the active site of the enzyme, with glutamic acid being the key residue that donates a proton required for hydrolyzing the $\beta(1 \rightarrow 4)$ glycosidic bond in chitin [11]. In chitinase-like proteins, the substitution of this essential glutamic acid to leucine, isoleucine or glutamine accounts for the lack of chitinolytic activity (table 1). Nevertheless, they are still capable of binding to chitin with high affinity, as the conserved chitin-binding aromatic residues on the triose-phosphate isomerase barrel remains unaffected $[12,13]$. Both humans and mice express 2 enzymatically active forms of chitinases - chitotriosidase and AMCase. In contrast, there are only 3 enzymatically inactive forms of chitinase-like proteins in humans but 7 in mice $[9,10]$. The phylogenetic tree of human and mice GH18 family members is shown in figure 3, which further illustrates the extensive conservation of chitinase and chitinase-like proteins within the mammalian kingdom. Chitotriosidase was the first mammalian chitinase to be identified and has since been implicated in Gaucher disease, the most common lysosomal storage disorder in humans caused by an inherited deficiency in glucocerebrosidase [14]. AMCase was subsequently cloned as an acid-stable active enzyme and is highly expressed in the gastrointestinal tract, and to a lesser extent, in the lung and alveolar macrophages in both humans and mice $[15,16]$, with an optimum activity at $\mathrm{pH} 4-5$ [11].

\section{Chitinases in Host Immunity and Inflammation}

Human GH18 members are located on chromosome 1 adjacent to the major histocompatibility complex paralogon genes, implying a role of chitinases in innate and adaptive immunity [9]. Several lines of evidence have 


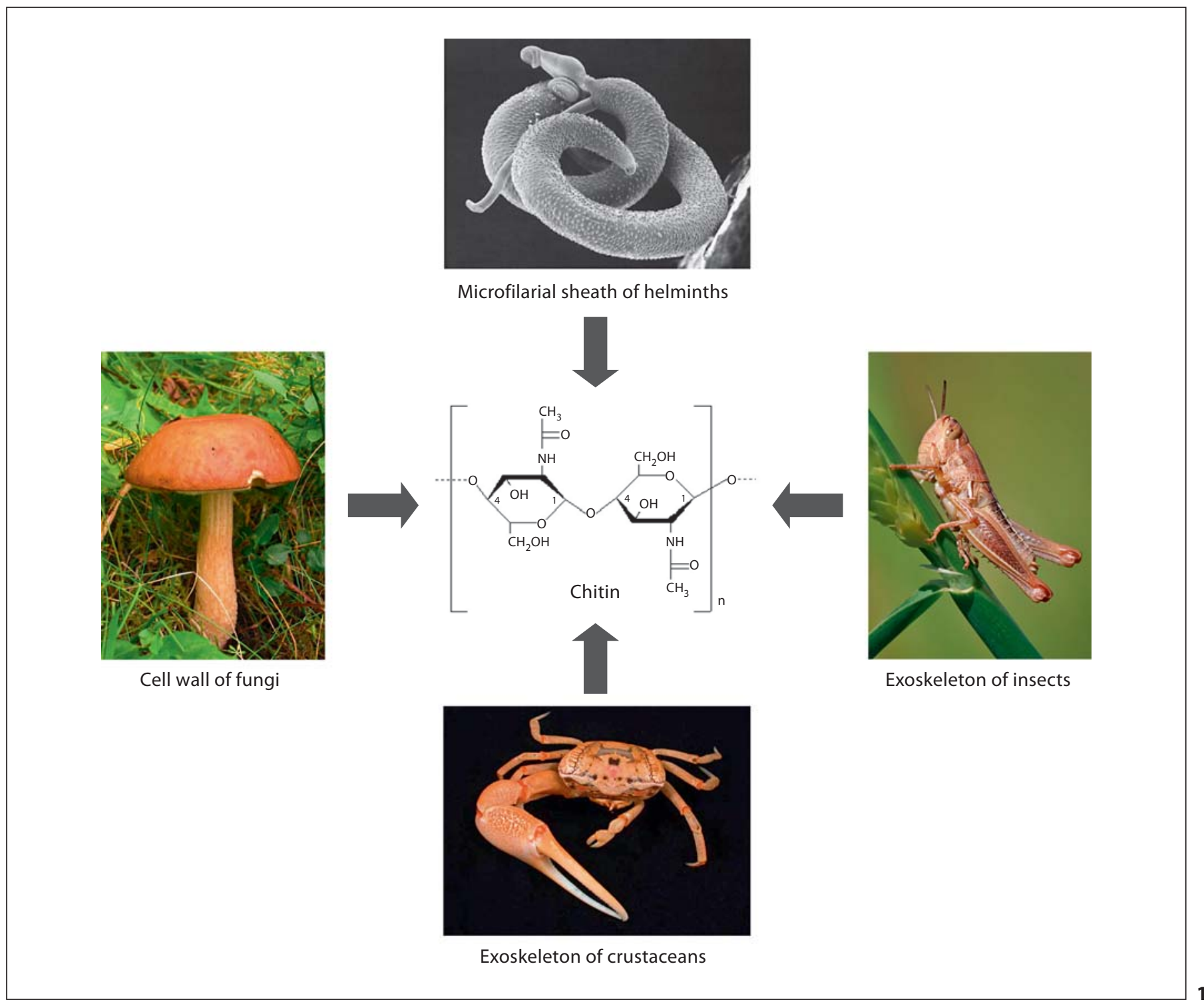

Fig. 1. Chitin is a homopolymer of $\beta(1 \rightarrow 4)$ linked N-acetyl-D-glucosamine residues. It is found in the cell wall of fungi, the microfilarial sheath of helminths and the exoskeleton of insects and crustaceans.

Fig. 2. 3D structure of human chitotriosidase (Protein Data Bank accession code $1 \mathrm{GUV}$ ), a chitinase of the GH18 family. The triosephosphate isomerase (TIM) barrel is made up of a cylinder of 8 parallel $\beta$-strands (pink) surrounded by 8 parallel $\alpha$-helices (blue). The conserved active site sequence motif for chitotriosidase lies within $\beta_{4}$ (cyan) and is shown with the critical glutamic acid residue (E) indicated in red and as ball and stick model. This residue is responsible for mediating the protonation of the glycosidic bond in chitin. The $\alpha+\beta$ folding domain contains a mixture of $\beta$-strands and $\alpha$-helices (green). $\mathrm{D}=$ Aspartic acid; $\mathrm{G}=$ glycine; $\mathrm{L}=$ leucine; $\mathrm{W}=$ tryptophan.

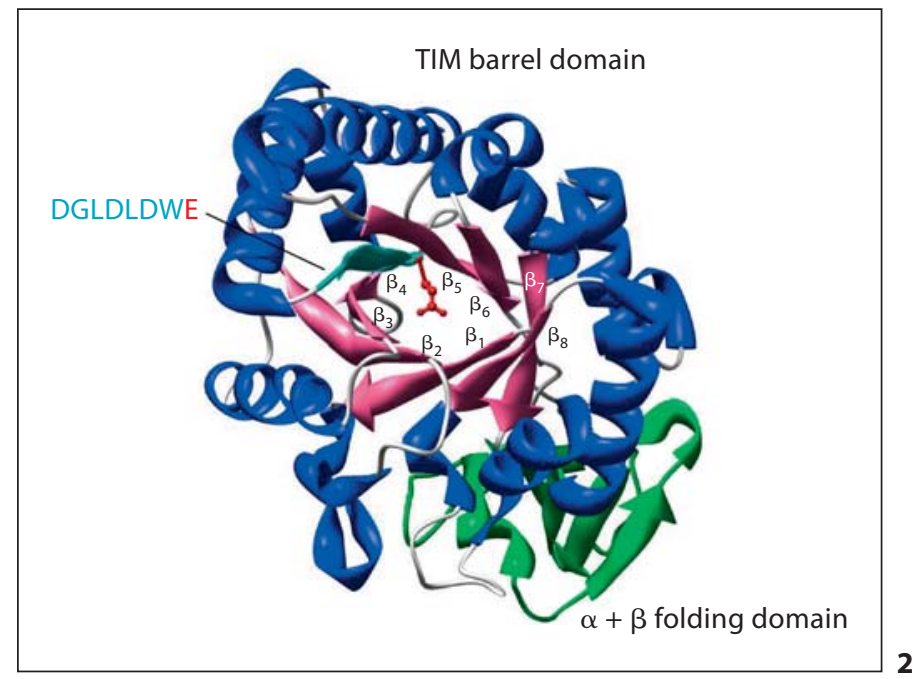

Chitinases and Asthma 
Table 1. Human and mouse GH18 family members

\begin{tabular}{llll}
\hline GH18 family & $\begin{array}{l}\text { Critical AA } \\
\text { at active site }\end{array}$ & Homo sapiens & Mus musculus \\
\hline $\begin{array}{l}\text { True chitinases } \\
\text { Chitotriosidase }\end{array}$ & E & CHIT1 (NM_003465) & Chit1 (NM_027979) \\
$\begin{array}{l}\text { AMCase } \\
\text { Chitinase-like proteins }\end{array}$ & E & CHIA (NM_621797) & Chia (NM_023186) \\
YKL-40 & L & CHI3L1 (NM_001276) & Chi311 (NM_007695) \\
Oviductin & L & OVGP1 (NM_002557) & Ovgp1 (NM_007696) \\
YKL-39 & I & CHI3L2 (NM_004000) & - \\
Ym1 & Q & - & Chi313 (NM_009892) \\
Ym2 & Q & - & Chi314 (NM_145126) \\
Ym3 & Q & - & Chi315 (NM_889251) \\
Bclp2 & Q & - & Bclp2 (NM_001080816) \\
BYm & Q & - & bYm (BC051070) \\
\hline
\end{tabular}

${ }^{1}$ The chitinolytic activity of GH18 family members is determined by a highly conserved sequence motif within the active site. The critical amino acid (AA) residue is shown, where $\mathrm{E}=$ glutamic acid, $\mathrm{L}=$ leucine, $\mathrm{I}=$ isoleucine and $\mathrm{Q}=$ glutamine. The presence of $\mathrm{E}$ at the active site renders the protein enzymatically active.

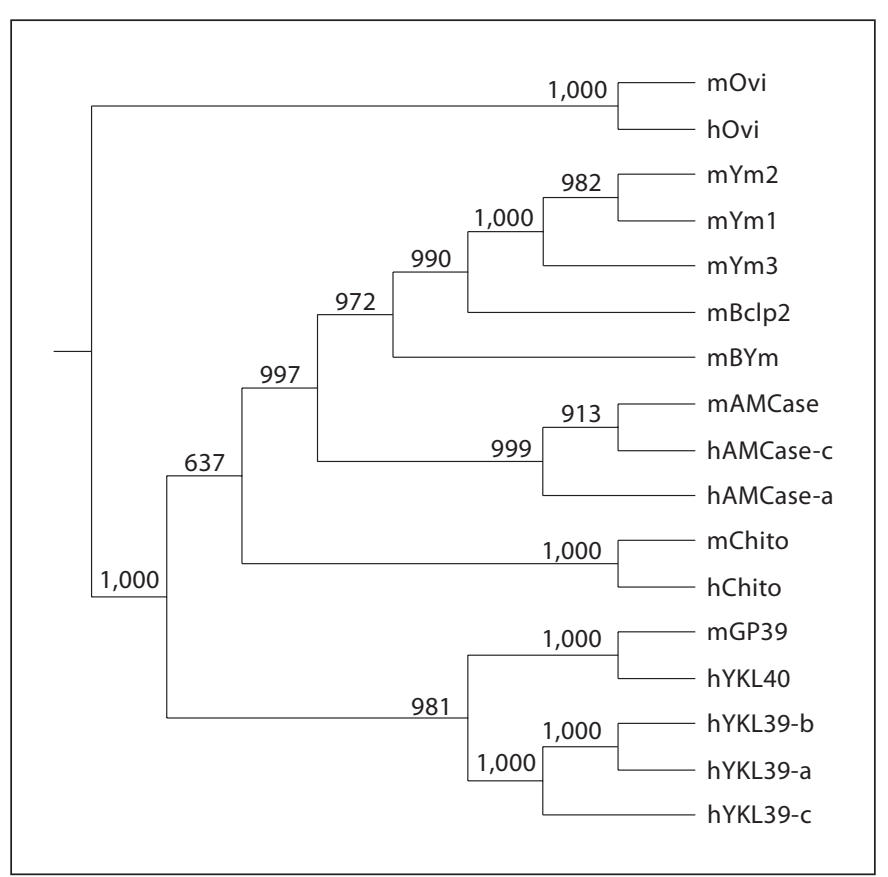

Fig. 3. A distance-based phylogenetic tree of GH18 family members present in humans (h) and mice $(\mathrm{m})$. The tree was created based on the protein alignment generated using CLC Main Workbench 4 . The UPGMA (unweighted pair group method with arithmetic mean) algorithm was utilized where evolutionary rates are assumed to be constant in the different lineages. To evaluate the reliability of the tree, a bootstrap analysis was performed on 1,000 replicates. The bootstrap value is denoted at each node as a measure of confidence in the respective branch. demonstrated the importance of chitinases as an effector of host defense in the mammalian immune system. For instance, humans that are deficient in chitotriosidase have an increased rate of microfilarial infection due to suppressed chitinolytic activity that allows the parasite to thrive within the host [17]. Recombinant human chitotriosidase has demonstrated anti-fungal activity by inhibiting Candida albicans hyphae formation in vitro and by reducing mortality in mouse models of neutropenic Candidiasis and Aspergillosis [18]. Therefore, the enzymatic activity of chitinases has an obvious protective role that is mediated through the degradation of the key structural component of pathogens - chitin. Notwithstanding, the enzymatically inactive chitinaselike proteins are not to be dismissed as inconsequential as they may play equally important roles in host defense against pathogens [7]. The fact that chitinase-like proteins retain the ability to bind chitin with high affinity implies that they may function in the recognition of pathogen-associated molecular patterns encoded in chitin, thereby signaling to the host immune system to mount an appropriate pathogen-directed attack. The host immunity role of chitinase-like proteins remains to be established.

On the other hand, the correlation between serum levels of mammalian chitinases and a variety of inflammatory conditions are well documented. Besides being a biomarker for Gaucher disease, chitotriosidase has been 
linked to atherosclerosis, nonalcoholic fatty liver disease and juvenile idiopathic arthritis [19-21]. The other prominent chitinase-like protein YKL-40 (also called chitinase-3-like 1 and human cartilage glycoprotein 39) has been studied extensively, and its elevated serum level has been linked to diseases like inflammatory bowel disease, liver fibrosis, rheumatoid arthritis and cancers [22, 23]. From the findings of these independent studies, it is quite clear that dysregulated chitinase expression is often associated with inflammatory conditions.

\section{Chitinase Levels and Asthma}

Asthma is a chronic inflammatory lung disease characterized by airway hyperreactivity and mucus hypersecretion that results in intermittent airway obstruction. At present, it is generally believed that atopic asthma is associated with the heightened activity of the Th2 arm of adaptive immunity. Th2 lymphocytes produce a characteristic array of cytokines that are implicated in the initiation and perpetuation of airway inflammation. Interleukin (IL)-4 and IL-13 stimulate B cell activation and class switching to immunoglobulin E production which are subsequently required to mediate mast cell degranulation. IL-5 is pivotal for the growth, differentiation, recruitment and survival of eosinophils, the main effector cells responsible for chronic inflammation in allergic asthma [24, 25].

As early as in 2001, Webb and coworkers [13] reported an upregulation of a chitinase-like protein $\mathrm{Ym} 2$ in mouse CD4+ Th2 lymphocytes in response to IL-4 and IL-13 signaling via the IL- $4 \mathrm{R} \alpha$ subunit. The bronchoalveolar lavage (BAL) fluid levels of Ym 2 and $Y \mathrm{~m} 1$ from an allergic mouse asthma model and from mice treated with intratracheal IL-13 were also elevated. Subsequently, in an allergic peritonitis mouse model, Ym1 protein expression in macrophages was shown to be IL- 4 and signal transducers and activators of transcription 6 dependent [26]. These are the first indications of the involvement of chitinases in allergic airway inflammation. As Ym1 and Ym2 are chitinase-like proteins lacking enzymatic activity, and have been shown to bind to carbohydrates such as heparin/heparan sulfate [27] and promote cell migration [28], the authors postulated that Ym1 and Ym2 may participate in airway inflammation and/or tissue remodeling. However, Ym1 (chitinase-3-like 3) and Ym2 (chitinase-3-like 4) genes are restricted to the mouse genome, and there are no human orthologs for further clinical investigation.

Chitinases and Asthma
The first clinically relevant finding regarding the role of chitinase in asthma was reported by Zhu and coworkers [8] where exaggerated quantities of AMCase were detected in the epithelial cells and macrophages of lung biopsies taken from patients with asthma. Correspondingly, the AMCase level and BAL fluid chitinase activity were also induced in the lungs of a ovalbumin-induced mouse asthma model. Using a similar acute mouse asthma model, upregulation of both lung AMCase and Ym1 gene expression was detected by a DNA microarray study [29], and concurrent elevation of the BAL fluid protein level of AMCase, Ym1 and Ym2 was also observed using a 2D gel electrophoresis proteomics approach [30]. In contrast, no change was observed in chitotriosidase protein level in BAL fluids. In a chronic mouse asthma model, only AMCase and Ym2 proteins but not Ym1 were found to be upregulated in the proteomes of lung tissues and/or BAL fluid [31]. In line with the observations in allergic airway inflammation, the AMCase level and/or activity have also been found upregulated in tears of subjects with ocular allergies [32] and with chronic rhinosinusitis with nasal polyps [33].

Besides AMCase, serum and lung tissue levels of a chitinase-like protein YKL-40 have recently been found to be increased in patients with asthma. Furthermore, circulating YKL-40 levels correlated positively with asthma severity, thickening of the lung subepithelial basement membrane, frequency of rescue inhaler use, and deterioration in pulmonary function in asthmatic subjects studied [34]. To substantiate this novel finding, Kuepper and coworkers [35] presented follow-up data demonstrating significantly higher levels of YKL-40 in both serum and BAL fluid of asthmatic patients after they were challenged with various allergens.

On the other hand, recent pharmacoproteomics studies of BAL fluid from aeroallergen-challenged mice revealed that corticosteroid drug dexamethasone and cysteinyl leukotriene receptor antagonist MK-571 were able to suppress the upregulation of AMCase, Ym1 and Ym2 levels, together with concomitant anti-inflammatory effects in a mouse asthma model $[36,37]$. In an attempt to explore potential anti-inflammatory effects of a glycogen synthase kinase- $3 \beta$ inhibitor TDZD-8 in a mouse asthma model, Bao and coworkers [38] reported not only anti-inflammatory actions of TDZD-8 in asthma but also downregulation of AMCase, Ym1 and $\mathrm{Ym} 2$ gene expression in allergen-induced inflamed lungs. Taken together, we have compelling evidence to support the notion that YKL-40 and AMCase levels may be useful biomarkers for Th2-dependent allergic airway inflammation, and the 
Table 2. Expression levels of chitinases in asthma

\begin{tabular}{llllll}
\hline Chitinase & Organism & Model & Level & $(+)$ Drug treatment & Reference \\
\hline Ym1 & mouse & acute & $\uparrow$ & $\downarrow$ & $26,28,34,35,36$ \\
Ym2 & mouse & chronic & no change & - & 29 \\
& mouse & acute & $\uparrow$ & $\downarrow$ & $13,28,34,35,36$ \\
AMCase & mouse & chronic & $\uparrow$ & not determined & 29 \\
& mouse & acute & $\uparrow$ & $\downarrow$ & $8,27,28,34,35,36$ \\
& mouse & chronic & $\uparrow$ & not determined & 29 \\
YKL-40 & human & - & $\uparrow$ & not determined & $8,41,42$ \\
Chitotriosidase & human & - & $\uparrow$ & not determined & 32,33 \\
& mouse & acute & no change & - & 28 \\
& mouse & chronic & no change & - & 29 \\
& human & - & no change & - & 43 \\
\hline
\end{tabular}

AMCase level may be useful for monitoring the effectiveness of anti-inflammatory therapy in asthma (table 2). Nevertheless, a large-scale multicenter association study is urgently needed to firmly establish the biomarker role of chitinases in asthma.

\section{Chitinase Polymorphism and Asthma Susceptibility}

As chitin is abundantly expressed in our environment, constant exposure to prodigious amounts of chitin may trigger off allergic responses. Indeed, intranasal administration of chitin to mice induced pulmonary infiltration of IL-4-expressing immune cells such as eosinophils and basophils [39]. An epidemiological study also showed that asthma is a common occupational hazard among shellfish processors as they are relentlessly overwhelmed by the high levels of chitin in their working environment [40]. It is tempting to speculate that individuals expressing variant forms of the true chitinase enzymes with enhanced activity are more susceptible to bronchial asthma. Indeed, genetic variants in AMCase (a single amino acid exchange K17R and nearby noncoding polymorphism rs3818822 in a German cohort with bronchial asthma, and a noncoding polymorphism rs 3806448 in an Indian cohort with atopic asthma) have been found to be strongly associated with bronchial asthma and/or serum immunoglobulin E levels and supporting the involvement of AMCase in asthma $[41,42]$. In contrast, a study of genetic variants of the other true chitinase chitotriosidase failed to reveal any association with asthma development [43].
Interestingly, CHI3L1, the gene that encodes for a chitinase-like protein YKL-40, has recently been shown to be highly heritable and associated with susceptibility to asthma. A single-nucleotide polymorphism in the promoter region of CHI3L1 (rs4950928, $-131 \mathrm{C} \rightarrow \mathrm{G})$ causes a disruption of the binding site for transcription factors leading to a reduction in basal YKL-40 expression. Besides diminishing serum YKL-40 levels, the variant $-131 \mathrm{G}$ allele is also associated with protection against asthma, bronchial hyperresponsiveness and reduced lung function [44]. These findings imply that YKL-40 may have a direct causal role in the pathogenesis of asthma, but the exact role remains to be established [45].

\section{Mechanism of Chitinases in Asthma}

In an aeroallergen mouse asthma model, AMCase expression in airway epithelial cells and macrophages was found to be Th2 cytokine IL-13 dependent, and neutralization of AMCase using anti-AMCase sera or a pan-chitinase inhibitor allosamidin diminished lung eosinophilia and lymphocyte accumulation probably by suppressing the production of chemokines such as eotaxin, monocyte chemotactic protein (MCP)-1, MCP-2, macrophage inflammatory protein-1 $\beta$ and ENA-78. These effects collectively led to an attenuation of airway inflammation and airway hyperresponsiveness (fig. 4) [8]. These findings suggest that AMCase has a pathophysiological role in asthma and the potential to be a therapeutic target for asthma. In line with these findings, intratracheal inoculation of Cryptococcus neoformans, a fungus that consists of chitin, induces AMCase 


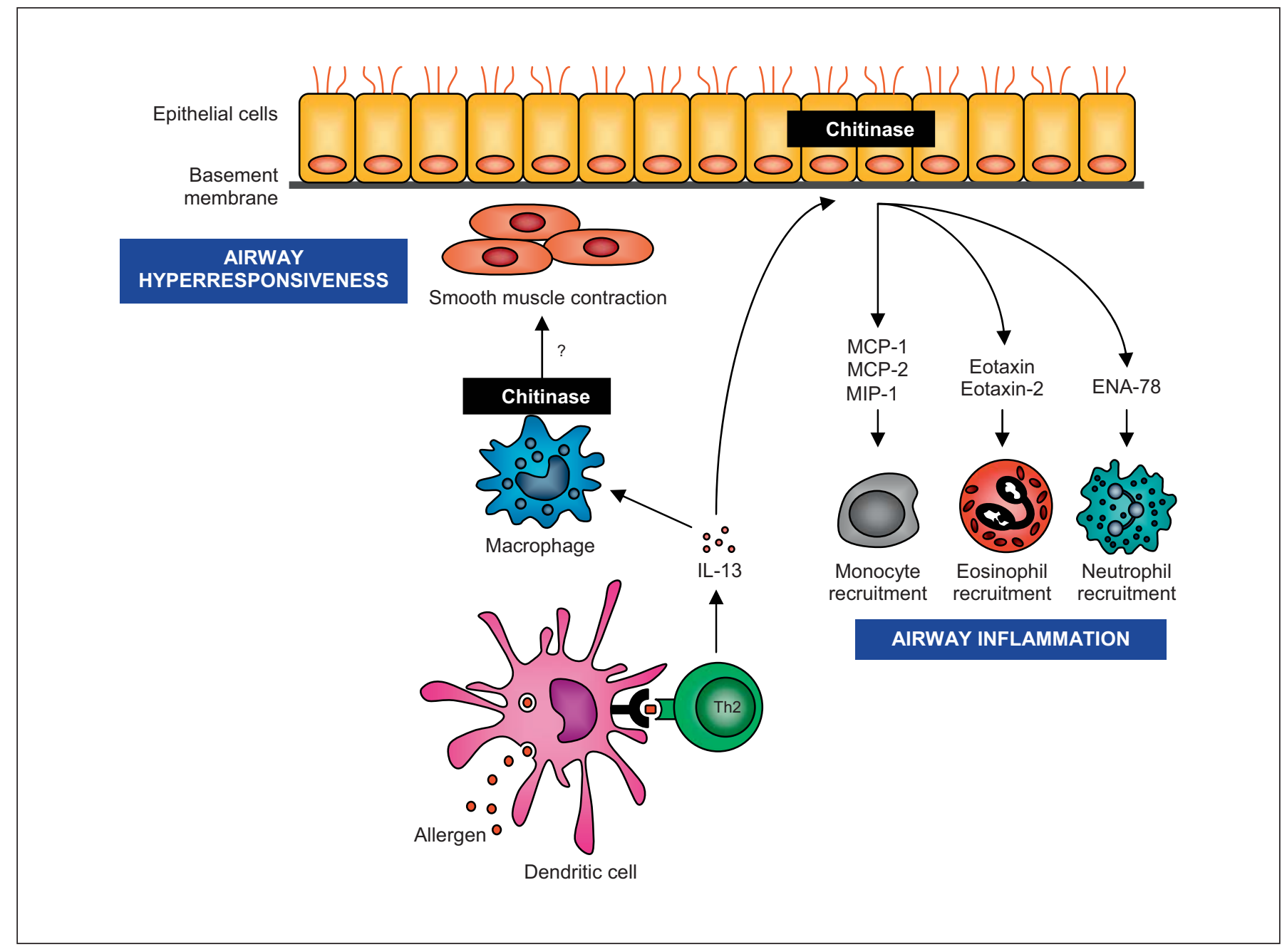

Fig. 4. The proposed role of AMCase in the pathogenesis of asthma. Th 2 cells release IL-13 which potently and selectively induces the expression of chitinase in airway epithelial cells and alveolar macrophages. Chitinase expression in epithelial cells may stimulate the release of (1) MCP-1, MCP-2 and macrophage inflammatory protein (MIP)-1 $\beta$ which especially recruit monocytes, (2) eo- taxin and eotaxin-2 which specifically recruit eosinophils, and (3) ENA-78 which specifically recruit neutrophils into the airways resulting in airway inflammation. Chitinase expression in macrophages may directly evoke smooth muscle contraction manifested as airway hyperresponsiveness. expression in the lung of infected rats. As chronic pulmonary C. neoformans infection leads to enhanced allergic inflammation, it is likely that AMCase is the possible link between respiratory fungal infection and asthma [46].

YKL-40 is by far the most studied human GH18 chitinase. YKL-40 has been shown to induce activation of the mitogen-activated protein kinase pathway, protein kinase $\mathrm{B}(\mathrm{Akt})$ pathway and nuclear factor- $\kappa \mathrm{B}$ transcriptional activity in cell cultures like human colon cell lines and human chondrocytes and synovial cells. Although it lacks chitinolytic activity, YKL-40 can still bind to chitin, heparin, hyaluronan and type I collagen and is believed to play a role in the process of inflammation and tissue remodeling $[22,23]$. However, the exact role of YKL-40 in the pathogenesis of asthma is unknown. Therefore, substantially more research works using knockout mice, recombinant chitinases and siRNA technology are required to investigate the potential role of chitinases like AMCase and YKL-40 in the pathogenesis of asthma. 


\section{Conclusions}

The evolutionary conserved chitinase GH18 family members were originally thought to function solely in primordial innate immune responses to chitin-containing parasites. However, recent studies have demonstrated a strong association of these enzymes, at least AMCase and YKL-40, in Th2-associated inflammatory diseases such as bronchial asthma. In an aeroallergen-induced asthma model, the elevated levels of chitinases can be downregulated by anti-inflammatory drug treatment. These findings warrant further clinical investigations on the potential role of AMCase and YKL-40 as biomarkers for assessing asthma severity and for monitoring antiasthma therapy. On the other hand, the causal relationship between the level of AMCase and YKL-40 and asthma development has not been unequivocally established. Tremendous cellular and molecular studies in animal models on establishing the pathogenic role of AMCase and YKL-40 in asthma remain to be carried out.

\section{Acknowledgement}

This work was partly supported by an Academic Research Fund grant R-184-000-130-112 from the National University of Singapore to W.S.F.W.

\section{References}

1 Beasley R, Crane J, Lai CK, Pearce N: Prevalence and etiology of asthma. J Allergy Clin Immunol 2000;105:S466-S472.

-2 Masoli M, Fabian D, Holt S, Beasley R: The global burden of asthma: executive summary of the GINA Dissemination Committee report. Allergy 2004;59:469-478.

-3 O'Sullivan SM: Asthma death, CD8+ T cells, and viruses. Proc Am Thorac Soc 2005;2: 162-165.

4 Braman SS: The global burden of asthma. Chest 2006;130:4S-12S.

5 Elias JA, Homer RJ, Hamid Q, Lee CG: Chitinases and chitinase-like proteins in $\mathrm{TH} 2$ inflammation and asthma. J Allergy Clin Immunol 2005; 116:497-500.

6 Latge JP: The cell wall: a carbohydrate armour for the fungal cell. Mol Microbiol 2007; 66:279-290.

7 Dickey BF: Exoskeletons and exhalation. N Engl J Med 2007;357:2082-2084.

-8 Zhu Z, Zheng T, Homer RJ, Kim YK, Chen NY, Cohn L, Hamid Q, Elias JA: Acidic mammalian chitinase in asthmatic Th2 inflammation and IL-13 pathway activation. Science 2004;304:1678-1682.

9 Funkhouser JD, Aronson NN Jr: Chitinase family GH18: evolutionary insights from the genomic history of a diverse protein family. BMC Evol Biol 2007;7:96-111.

$\checkmark 10$ Bussink AP, Speijer D, Aerts JM, Boot RG: Evolution of mammalian chitinase(-like) members of family 18 glycosyl hydrolases. Genetics 2007;177:959-970.

-11 Chou YT, Yao S, Czerwinski R, Fleming M, Krykbaev R, Xuan D, Zhou H, Brooks J, Fitz L, Strand J, Presman E, Lin L, Aulabaugh A, Huang X: Kinetic characterization of recombinant human acidic mammalian chitinase. Biochemistry 2006;45:4444-4454.
12 Fusetti F, Pijning T, Kalk KH, Bos E, Dijkstra BW: Crystal structure and carbohydratebinding properties of the human cartilage glycoprotein-39. J Biol Chem 2003;278: 37753-37760.

13 Webb DC, McKenzie AN, Foster PS: Expression of the Ym2 lectin-binding protein is dependent on interleukin (IL)-4 and IL-13 signal transduction: identification of a novel allergy-associated protein. J Biol Chem 2001; 276:41969-41976.

14 Bussink AP, van Eijk M, Renkema GH, Aerts JM, Boot RG: The biology of the Gaucher cell: the cradle of human chitinases. Int Rev Cytol 2006;252:71-128.

15 Boot RG, Blommart EF, Swart E, Ghauharali-van der Vlugt K, Bijl N, Noe C, Place A, Aerts JM: Identification of a novel acidic mammalian chitinase distinct from chitotriosidase. J Biol Chem 2001;276:67706778.

16 Boot RG, Bussink AP, Verhoek M, de Boer PA, Moorman AF, Aerts JM: Marked differences in tissue-specific expression of chitinases in mouse and man. J Histochem Cytochem 2005;53:1283-1292.

17 Choi EH, Zimmerman PA, Foster CB, Zhu S, Kumaraswami V, Nutman TB, Chanock SJ: Genetic polymorphisms in molecules of innate immunity and susceptibility to infection with Wuchereria bancrofti in South India. Genes Immun 2001;2:248-253.

18 van Eiji M, van Roomen CP, Renkema GH, Bussink AP, Andrews L, Blommaart EF, Sugar A, Verhoeven AJ, Boot RG, Aerts JM: Characterization of human phagocyte-derived chitotriosidase, a component of innate immunity. Int Immunol 2005; 17:15051512 .
Artieda M, Cenarro A, Ganan A, Jerico I, Gonzalvo C, Casado JM, Vitoria I, Puzo J, Pocovi M, Civeira F: Serum chitotriosidase activity is increased in subjects with atherosclerosis disease. Arterioscler Thromb Vasc Biol 2003;23:1645-1652.

20 Malaguarnera L, Di Rosa M, Zambito AM, dell'Ombra N, Niceoletti F, Malaguarnera M: Chitotriosidase gene expression in Kupffer cells from patients with non-alcoholic fatty liver disease. Gut 2008;55:1313-1320.

21 Brunner JK, Scholl-Bürgi S, Hössinger D, Wondrak P, Prelog M, Zimmerhackl LB: Chitotriosidase activity in juvenile idiopathic arthritis. Rheumatol Int 2008;28:949950.

22 Johansen JS: Studies on serum YKL-40 as a biomarker in diseases with inflammation, tissue remodeling, fibroses and cancer. Dan Med Bull 2006;53:172-209.

23 Kawada M, Hachiya Y, Arihiro A, Mizoguchi E: Role of mammalian chitinases in inflammatory conditions. Keio J Med 2007;56: 21-27.

24 Medoff BD, Thomas SY, Luster AD: T cell trafficking in allergic asthma: the ins and outs. Annu Rev Immunol 2008;26:205-232.

25 Hogan SP, Rosenberg HF, Moqbel R, Phipps S, Foster PS, Lacy P, Kay AB, Rothenberg ME: Eosinophils: biological properties and role in health and disease. Clin Exp Allergy 2008;38:709-750.

26 Welch JS, Escoubet-Lozach L, Sykes DB, Liddiard K, Greaves DR, Glass CK: TH2 cytokines and allergic challenge induced Ym1 expression in macrophages by a STAT6-dependent mechanism. J Biol Chem 2002;277: 42821-42829.

27 Chang NC, Hung SI, Hwa KY, Kato I, Chen JE, Liu CH, Chang AC: A macrophage protein, Ym1, transiently expressed during inflammation is a novel mammalian lectin. J Biol Chem 2001;276:17497-17506. 
28 Malinda KM, Ponce L, Kleinman HK, Shackelton LS, Millis AJ: Gp38k, a protein synthesized by vascular smooth muscle cells, stimulates directional migration of human umbilical vein endothelial cells. Exp Cell Res 1999;250:168-173.

-29 Zimmermann N, Mishra A, King NE, Fulkerson PC, Doepker MP, Nikolaidis NM, Kindinger LE, Moulton EA, Aronow BJ, Rothenberg ME: Transcript signatures in experimental asthma: identification of STAT6dependent and -independent pathways. J Immunol 2004;172:1815-1824.

-30 Zhao J, Zhu H, Wong CH, Leung KY, Wong WS: Increased lungkine and chitinase levels in allergic airway inflammation: a proteomics approach. Proteomics 2005;5:27992807.

-31 Wong WS, Zhao J: Proteome analysis of chronically inflamed airways in a mouse chronic asthma model. Int Arch Allergy Immunol 2008;147:179-189.

-32 Musumeci M, Bellin M, Maltese A, Aragona P, Bucolo C, Musumeci S: Chitinase levels in the tears of subjects with ocular allergies. Cornea 2008;27:168-173.

-33 Ramanathan M Jr, Lee WK, Lane AP: Increased expression of acidic mammalian chitinase in chronic rhinosinusitis with nasal polyps. Am J Rhinol 2006;20:330-335.
34 Chupp GL, Lee CG, Jarjour N, Shim YM, Holm CT, He S, Dziura JD, Reed J, Coyle AJ, Kiener P, Cullen M, Grandsaigne M, Dombret MC, Aubier M, Pretolani M, Elias JA: A chitinase-like protein in the lung and circulation of patients with severe asthma. N Engl J Med 2007;357:2016-2027.

35 Kuepper M, Bratke K, Virchow JC: Chitinase-like protein and asthma. N Engl J Med 2008;358:1073-1075.

36 Zhao J, Yeong LH, Wong WS: Dexamethasone alters bronchoalveolar lavage fluid proteome in a mouse asthma model. Int Arch Allergy Immunol 2007;142:219-229.

37 Wong WSF, Zhu H, Liao W: Cysteinyl leukotriene receptor antagonist MK-571 alters bronchoalveolar lavage fluid proteome in a mouse asthma model. Eur J Pharmacol 2007; 575:134-141.

38 Bao Z, Lim S, Liao W, Lin Y, Thiemermann C, Leung BP, Wong WS: Glycogen synthase kinase-3 $\beta$ inhibition attenuates asthma in mice. Am J Respir Crit Care Med 2007;176 431-438.

39 Reese TA, Liang HE, Tager AM, Luster AD, Van Rooijen N, Voehringer D, Locksley RM Chitin induces accumulation in tissue of innate immune cells associated with allergy. Nature 2007;447:92-96.

40 Cartier A, Lehrer SB, Horth-Susin L, Swanson $\mathrm{M}$, Neis B, Howse D, Jong M: Prevalence of crab asthma in crab plant workers in Newfoundland and Labrador. Int J Circumpolar Health 2004;63:333-336.
41 Bierbaum S, Nickel R, Koch A, Lau S, Deichmann KA, Wahn U, Superti-Furga A, Heinzmann A: Polymorphisms and haplotypes of acid mammalian chitinase are associated with bronchial asthma. Am J Respir Crit Care Med 2005;172:1505-1509.

-42 Chatterjee R, Batra J, Das S, Sharma SK, Ghosh B: Genetic association of acidic mammalian chitinase with atopic asthma and serum total IgE levels. J Allergy Clin Immunol 2008;122:202-208.

-43 Bierbaum S, Superti-Furga A, Heinzmann A: Genetic polymorphisms of chitotriosidase in Caucasian children with bronchial asthma. Int J Immunogenet 2006;33:201-204.

44 Ober C, Tan Z, Sun Y, Possick JD, Pan L, Nicolae R, Radford S, Parry RR, Heinzmann A, Deichmann KA, Lester LA, Gern JE, Lemanske RF Jr, Nicolae DL, Elias JA, Chupp GL: Effect of variation in CHI3L1 on serum YKL-40 level, risk of asthma, and lung function. N Engl J Med 2008;358:1682-1691.

45 Moffatt MF, Cookson WO: Asthma and chitinases. N Engl J Med 2008;358:1725-1726.

46 Vicencio AG, Narain S, Du Z, Zeng WY, Ritch J, Casadevall A, Goldman DL: Pulmonary cryptococcosis induces chitinase in the rat. Respir Res 2008;9:40. 